\title{
DUAS ENTREVISTAS
}

\section{Ana Luísa Amaral}

\section{UM LIVRO É UMA BOMBA A ESTALAR REVOLUC̄̃̃ES*}

Rita Freire: Acaba de editar Ara, o seu primeiro romance, aos 57 anos. Por que agora?

Ana Luísa Amaral: Algumas coisas têm vindo a ser pensadas há muito tempo. Na apresentação do livro, agradeci a Maria Velho da Costa por ter lido e gostado. Não me atrevia a publicar, até porque se trata de um livro híbrido, não há personagens, não há acção, propriamente dita. Mas há, ao longo dos vários capítulos, que são de natureza diversa e temáticas diferentes, há vozes, um espaço, e fios condutores, povoados por nós [laços] e nós [pessoas]. E, se quisesse expandir ainda a homofonia, diria que a este livro se poderia aplicar a metáfora da noz [fruto], deixada a navegar, em deriva. Alguns desses capítulos trabalham sobre a escrita, outros sobre o amor, outros sobre a resistência, até a política.

RF: O que a fez sair da poesia para a prosa?

ALA: Nunca abandono a poesia. Na apresentação do livro reparei que batia com o pé, à medida que ia lendo. Faço isso ao ler poesia. Mas nunca diria que isto é um poema em prosa. Também não é prosa poética. Mas de vez em quando é poesia.

RF: Como o vê?

ALA: Como romance, vejo-o numa linhagem que se inscreve no modernismo. O que são As Ondas, de Virginia Woolf? São vozes. O que é a parte final de $A$ Noite e o Riso, de Nuno Bragança? São fragmentos. O que é grande parte dos textos de Ulisses, de Joyce? O hibridismo não é uma coisa nova. Vejo este meu romance num espaço ligado à forma como defino a minha poesia: o espaço intermédio.

RF: Sentia necessidade de contar algo a que a poesia não servisse?

ALA: Não. Pareceu-me mais natural escrever assim. Na abertura, digo: "Mas as coisas não giram ao nosso compasso. Eu não sou romancista". É uma espécie de diálogo interior e com o leitor, embora não tenho sido escrito com essa intenção. Não tenho nenhuma intenção quando escrevo, escrevo porque preciso. Se não tivesse editora, continuaria a escrever.

* Entrevista a Rita Silva Freire; texto revisto e aumentado por Ana Luísa Amaral. Publicado no Jornal Sol, Lisboa, 6 de Janeiro de 2013 
RF: O início do livro decorre na infância, entre o Sul e o Norte. É autobiográfico?

ALA: A vida está sempre presente na escrita. A literatura faz parte do mundo, não é, em termos de linguagem e na sua génese, diferente da língua que falamos no dia a dia. Embora crie uma dimensão de língua própria, quase uma gramática. Eu gostava de ter criado uma gramática - que fosse povoada. Acho que a equação literatura+vida estaria aí.

RF: Em que sentido?

ALA: O poema de Fernando Pessoa "Isto", diz: "Por isso escrevi em meio do que não está ao pé". O que está ao pé é a vida, o mundo. Escrevo num espaço que partilha o que está ao meu lado, mas que também não partilha o que lhe está tangente. É isso que faz a literatura: cria um universo próprio mas, a unir esse universo, estão sempre pequenos rastos que o ligam a vida. As minhas histórias pessoais não interessam às pessoas. Quem me conhece pode reconhecer coisas neste livro. Quem não me conhece não reconhecerá. Eu podia ter vivido sempre no Norte e ter criado uma voz que imaginasse ficar dividida entre o Norte e o Sul. Quando a minha mãe leu o livro disse-me: "a doença do teu avô não foi no Natal, foi em Junho". Há essa dimensão da vida. Mas gostaria que ela não fosse constantemente trazida para a discussão. Não interessa nada.

RF: Há uma relação de amor entre duas mulheres...

ALA: Sim, mas isso que tem? É uma relação de amor que não entra no normativo. As linhas enunciadoras resumem-se a duas frases: "Vergonha é consentir", "vergonha é não amar". Há tantas coisas de que ter vergonha: vergonha é a fome, vergonha é existirem sem-abrigo e nós nem os olharmos... Vergonha é esta política crudelíssima, de uma impunidade a que as palavras não chegam. Depois, há o desejo de inventar uma língua nova, uma nova litania, palavras novas. Mas, como diz Adrienne Rich, eu só tenho esta língua. Esta é a linguagem do opressor e, todavia, preciso dela para falar. Não há outra.

RF: Que dissonância é esta que assume no romance um papel preponderante?

ALA: Dissonância em termos sociais e em termos de afectos. Quis falar do dissonante em relação ao normativo, ao discurso dominante. É o dissonante no sentido em que se desvia daquilo que se que se espera de um género literário sob o qual o livro se abriga. É o dissonante pela instabilidade de colocação das várias vozes que vão povoando o livro, como num capítulo que se chama "Discrepâncias a duas vozes", um diálogo sobre a vida, o amor e a escrita. Repare-se: "ara" é uma palavra composta por três letras que existem na palavra 'palavra'. Além disso, como é sugerido no final, onde se lê "as palavras cruzadas no jornal", a palavra "ara" é fundamental para as palavras cruzadas. "Ara" é ainda uma capicua - do avesso. Esse final exprime, como de resto todo o livro, o desejo de uma utopia: uma utopia amorosa, uma utopia literária, uma utopia da língua, uma utopia da vida.

RF: As duas mulheres estão presas nos costumes. Ainda há vergonha no amor?

ALA: Sim. Mas tento no livro que essa vergonha seja, por assim dizer, "resolvida". Eu escrevi uma vez num poema: "O poema promete e compromete, / é filho, e como filho, obriga a tanto: / ser um filho emprestado a guerra alheia, / outra bomba a estalar revoluções na 
perigosa / ternura de outro olhar". Um livro pode ser outra bomba a estalar revoluções. Queria que as diferenças passassem a ser indiferenças, melhor, in-diferenças. A ideia de diferença cria hierarquizações. Há neste livro o desejo das não hierarquias: a não hierarquia do género e dos géneros, a não hierarquia das escritas, a não hierarquia dos amores e a não hierarquia das formas de se ser e de se estar na vida.

RF: A mulher tem lugar de destaque na sua escrita. A mulher já encontrou o seu espaço ou está ainda subjugada?

ALA: De que mulher falamos? Não há mulher, há mulheres. E de que mulheres falamos? Em Novas Cartas Portuguesas, publicado em 1972, pode ler-se: “A mulher adúltera é ainda apedrejada de morte na Arábia Saudita". Isto continua a acontecer. Temos que pensar em termos globais. As mulheres não encontraram o seu espaço. É necessário reivindicá-lo. Preocupa-me muito, por exemplo, ver a violência doméstica a crescer brutalmente. A reivindicação dos direitos e da dignidade humana, do direito a ter direitos, da liberdade, são reivindicações que estão na ordem do dia, porque são prementes. E estendem-se à nossa vida diária, ao momento por que passamos e que nos engloba a todos e a todas: homens e mulheres, crianças, minorias, imigrantes e emigrantes, os sem abrigo e os sem terra, e todos aqueles que são espoliados, segregados, discriminados.

\section{RF: E na literatura?}

ALA: As mulheres, em geral, ainda não encontraram uma gramática própria. Era preciso, e mais uma vez penso em Adrienne Rich, encontrar uma língua comum, que nos pudesse dizer a todos e a todas e onde todas e todos se revissem. Uma língua que pudesse dizer tudo. Essa é a utopia. A literatura em si não discrimina, mas a técnica discrimina, a gramática discrimina, o pensamento discrimina, a crítica discrimina. Eu ensino uma cadeira de graduação que se chama Introdução aos Estudos Feministas. E pergunto muitas vezes aos meus alunos: quantas mulheres conhecem da literatura portuguesa da segunda metade do século XX? Eles enumeram algumas, começando pela primeira metade do século XX com Florbela Espanca e Irene Lisboa. Mas quando pergunto sobre o século XIX, a resposta é "nada". As mulheres estão ausentes da história literária... Mas eu não quero carpir, não me interessa a vitimização. Interessa-me pensar em termos humanos. Por isso é-me muito complicado hierarquizar violências. E é da violência do discurso, da língua, dos gestos sociais que tento falar.

RF: Mesmo num romance tão íntimo sobre o amor faz declarações políticas. Por que?

ALA: A segunda vaga do Feminismo tem alguma razão quando reivindica que o pessoal é o político. Não posso separar as duas esferas, por isso digo que me é tão difícil ver hierarquizar violências. Muita da esquerda fez isso ao dizer que às lutas das mulheres se sobrepunha a luta de classes ou os movimentos de libertação. Penso nos novos países de língua portuguesa, criados depois do 25 de Abril, onde que a questão das mulheres foi posta de lado com o argumento de que era mais importante construir uma nação. Não é mais importante. Não posso construir nada de bom, novo, digno, se uma parte dos que constituem a matéria dessa construção continuarem a sofrer indignidades. A construção de algo será sempre muito imperfeita se não contemplar os que são discriminados. Se os continuar a esquecer, discriminar 
e oprimir.

RF: Diz que vergonha é a fome nas crianças.

ALA: Agora vemos gente com fome. No Porto, em Lisboa, nas outras cidades do país. $\mathrm{Na}$ Grécia, a situação é ainda mais dramática. Tenho muito medo das novas convulsões sociais que vão surgir, sobretudo dos aproveitamentos por parte da extrema-direita, de grupos neonazis, a surgirem cada vez mais fortes por toda a Europa. Veja-se a Hungria e as medidas governamentais anti-semitas e contra os ciganos, as novas leis sobre os homossexuais e a proibição da interrupção voluntária da gravidez - e não será despiciente perguntar como é possível que a União Europeia mantenha a Hungria como país-membro. Ao nosso lado, em Espanha, foi passada há dois meses a revisão da lei que permitia a interrupção voluntária da gravidez, ou seja, o aborto é novamente proibido, como no tempo de Franco. Não nos esqueçamos que Hitler chegou ao poder através de eleições. Os números de aderentes à Aurora Dourada, na Grécia, ou aos grupos franceses de extrema-direita estão a aumentar de forma assustadora. O momento é de profunda crise. Tenha-se um povo com pouca cultura, soneguemse as bases da educação e retire-se o direito a uma vida digna - e tem-se pessoas que, por estarem indignadas e revoltadas, podem ser convencidas de que a salvação está naquelas promessas de uma nova dignidade e da restauração do orgulho pátrio. Julgo que é Amartya Sen que recorda que democracia não significa só o direito a um voto por pessoa, mas que cada pessoa tenha uma voz. A democracia corre hoje profundos riscos. O que está a acontecer na Europa é assustador. Não só pela possibilidade de convulsões sociais, mas pela possibilidade de uma nova guerra. Pessoas com quem falo acham que estou a ser catastrófica, mas não o vejo assim. Como digo, Hitler chegou ao poder através das eleições. Os partidos extremistas não precisam de deter a maioria, porque a sua táctica é a da intimidação. A esquerda está partida, dividida, fragmentada, não se une, não tem uma alternativa. E isso é um imenso erro. A esquerda devia unir-se. E as pessoas de bem: honestas, não corruptas, acreditando na possibilidade de mudar este estado de coisas.

RF: Falávamos da fome que refere no livro.

ALA: Há muitos anos, no Porto, fiz voluntariado, distribuindo alimentos aos sem-abrigo. Havia uma carrinha. Agora há várias. Os pobres e a classe média estão a ser espoliados. E não me refiro só a salários: refiro-me a dignidade. Por exemplo, antigamente, os banqueiros estavam nos seus gabinetes; agora, porque a alta finança domina tudo, estão na televisão e nos jornais a falarem como se fossem políticos. E vêm dizer que o povo português aguenta, e aguenta muito bem... Isto é uma afronta. Eu vivo em Leça da Palmeira, uma zona piscatória, vejo senhores e senhoras de idade que vão aos correios buscar a sua reforma. Entram, com os seus xailes ou coturnos, e recebem 220, 225 euros. Como se pode viver assim com dignidade? O fito é o grande investimento, quando a espinha dorsal do nosso país é o pequeno e o médio comércio, não os grandes investidores, que mandam o dinheiro para fora do país, de forma a pagarem menos impostos. Essa é também a vergonha.

RF: Mas o livro acaba com uma nota de esperança. Que sonho é esse?

ALA: É uma utopia possível. Acredito que é possível mudar este estado de coisas. 
Acredito nas redes entre as pessoas, que as relações não têm de ser hierárquicas. Acredito que se criássemos uma língua nova era possível mudar o mundo. Justifica-se que ao escrevermos Homem com maiúscula nos estamos a referir à espécie humana? Pois muito bem. Então, se é assim tão inócuo, troque-se e ponha-se Mulher. Não dá, não funciona. São convenções. Pois, mas as convenções cristalizam as vidas e os hábitos, cristalizam a história e a cultura. Acredito que os impostos podem ser usados de forma solidária e correcta, acredito que era possível parar com a corrupção, com as fugas vergonhosas de capitais. E que é possível combater os ódios. Uma criança pequena não discrimina pela cor da pele. Isso é ensinado e aprendido. Acredito na cultura, que, ao apostarmos na cultura, estamos a ajudar a formar gente com capacidade de pensar melhor. E que, tendo gente a pensar, podemos criar uma nova gramática para o mundo. E para nós.

RF: Sendo que a cultura e a educação são áreas com um investimento cada vez menor. Como ultrapassar isso?

ALA: A cultura, a educação e a saúde - tal como eu as entendo, comuns e públicas - são as áreas mais frágeis, em que mais facilmente se desinveste. Como esta ideia peregrina de criar em Portugal um cheque-ensino. Em vez de se investir numa boa escola pública, privatiza-se a escola... Não se deseja que as universidades e as escolas se tornem lugares para produzir pensamento crítico, porque ele pode desestabilizar e, perdoe-me o pleonasmo, criticar, porque ele pode ser, portanto, uma ameaça ao sistema. Mas isso é a raiz da democracia: a voz e o acesso à voz. Por alguma razão, quando as ditaduras se instalam os primeiros a ir para a prisão são os intelectuais e os escritores. Não matam, coitados, não têm metralhadoras. Mas têm, de facto, outras armas. Por alguma razão se diz que Napoleão comentou uma vez, aquando da sua invasão da Itália: "Tenho mais medo de um jornal que de 100 mil baionetas". E, falando em arte e em Itália, pense-se como a letra do Coro dos Hebreus, de Nabucco, de Verdi, foi tão importante durante a ocupação austríaca. A palavra tem poder. E as humanidades têm vindo a ser esquecidas. Não se investe na filosofia, na literatura, nas artes, porque são as áreas que produzem discurso crítico.

RF: Mas também as que não geram emprego.

ALA: Mas geram outro tipo de capital: o intelectual, o pensamento humano, que também e património. As humanidades são áreas fundamentais que nos ajudam a sermos mais humanos. Se penso a partir da filosofia, ou a partir de um poema, estou a ocupar-me de algo que não é meramente ocioso e que, além de produzir pensamento crítico, contribui para algo de que precisamos profundamente e sem o qual ficamos em risco de nos perdermos: a dimensão estética, a beleza.

RF: Num momento em que o país atravessa uma crise em que, como diz, as pessoas têm fome, isso não se torna superficial?

ALA: Não. Isso é o que querem que nós acreditemos: que é preciso acorrer à pobreza e que, portanto, temos que cortar nas humanidades. É o mesmo problema da hierarquização. Nós temos necessidade de beleza, de contemplação. 
RF: Precisamos de pão, mas também de rosas?

ALA: Com certeza. Por alguma razão se diz que um dos grandes saltos na evolução humana se deu quando alguém começou a pôr flores nas campas. Nós precisamos do simbólico. E é esse pensamento sobre o simbólico que estamos a perder ao estraçalhar as humanidades e as artes.

RF: Vê isso como um objectivo em si mesmo ou acontece por falta de interesse?

ALA: Não sei se é uma conspiração consciente, no sentido de "agora não vamos investir na educação para que as pessoas não sejam convidadas a pensar mais", não sei se isto é sistematizado (às vezes, e sem querer entrar em teorias conspiratórias, julgo que é...). Mas é, com certeza, uma posição, uma forma de estar na vida e uma forma de encarar o mundo e as outras pessoas, reduzindo-nos a números. Para quem passou pelo 25 de Abril e acreditou que tudo era possível, isto é muito triste. Mas é preciso não baixar os braços. É preciso resistir, é preciso combater, na medida das nossas forças e com as armas que temos na mão, como dizia a canção em Portugal nos anos 70, adaptada de Victor Jara. A minha arma é a palavra. Sou contra a violência, mesmo quando a exerçam sobre nós. Mas denuncio-a como posso e sei. E sinto e sei que isto é uma violência, que estamos a sofrer violência.

RF: Ara é um livro de resistência?

ALA: É a minha forma de resistência a vários níveis. Também ao nível da normatividade dos afectos, de como as famílias podem ser organizadas, de como a vida amorosa e social pode ter uma nova organização. Não posso separar as coisas. Está tudo ligado. 


\section{DISCREPÂNCIAS A DUAS VOZES*}

Maria Teresa Coutinho: Que papel tem a infância na sua vida, o "tempo das regras decoradas e das terminações verbais" em que "sonhava de livro aberto"?

Ana Luísa Amaral: Eu acho que a infância tem, ainda, um papel preponderante na minha vida. Parece-me impossível alguém criar e ter aquilo a que se chama um "espírito adulto". E o que quero eu dizer com isto? Que continuo a comover-me com gestos insignificantes. Noutro dia dei por mim a chorar com "Monstros e Ca.", e não é comum as pessoas da minha idade comoverem-se com o mesmo. Era William Blake que dizia "To see a world in a grain of sand / and a heaven in a wild flower, / hold infinity in the palm of your hand / and eternity in an hour". E eu penso que ele constrói toda uma poesia que elogia a figura da criança, justamente porque, como dirá William Wordsworth, outro romântico, "A Criança é o Pai do Homem". Embora ligeiramente sexista, significa que a criança "sabe" mais do que o ser humano adulto. A infância tem, para mim, esse encanto e esse lado nostálgico, representando também uma forma de estar na vida. Não quer dizer que eu seja infantil, no sentido da "infantilização" do termo, mas valorizo muito um olhar disponível, aberto e inocente sobre as coisas. Eu acho que sou aberta a tudo, como uma criança.

MTC: Tive a ousadia de me apropriar de parte do seu poema "Coisas de Luz Antigas", onde diz:

$$
\begin{aligned}
& \text { A vida resvalante como gelo } \\
& \text { E aquele namorado de nome bom } \\
& \text { e férias, ficou perdido em luz, } \\
& \text { mais de vinte anos. }
\end{aligned}
$$

MTC: E eu pergunto, o que é que lhe provoca nostalgia?

ALA: Os irmãos que não tive, uma família grande que não tive. A saudade é construída sobre aquilo que se teve e se deixou de ter. A nostalgia, não. Eu tenho muito a nostalgia do que não tive e gostaria de ter. Elaboro muito sobre um universo ficcionado na minha cabeça e, portanto, perfeito. Assim, as minhas instâncias de nostalgia são relativamente a esse universo. Ou ainda por exemplo, a alguém que não posso ter, mas desejava. Eu tenho um poema que se chama "Natal a fingir branco", que refere mais ou menos isso: "a nostalgia de doer", ou seja, o Natal que não se teve. Há poucas coisas reais que me provoquem nostalgia. Tenho saudades, sim, tremendas, das pessoas que perdi, mas não tenho grandes penas na vida, dessas que me façam dizer "gostava muito de viver outra vez aquele momento". Acho que cada tempo é um tempo. Esse "namorado de nome bom em férias" existiu, é verdade, mas trata-se, acima de tudo, ali, no livro, de uma construção poética. Tenho nostalgia da construção poética e da vivência em torno dela, do namorado, não.

MTC: Sei que escreve desde muito nova. Teve, desde cedo, um quarto próprio para o fazer como aconselhava Virginia Woolf?

\footnotetext{
* Entrevista a Maria Teresa Freire Coutinho. Publicado no Jornal de Notícias, Porto, 2009.
} 
ALA: Não. Pode parecer estranho, sendo eu filha única e tendo vivido sempre com os meus pais, e bem, mas só o tive a partir dos catorze anos. No entanto, quando Virginia Woolf refere o tal "quarto que seja seu", não se refere apenas ao quarto físico mas também ao psicológico e à independência económica, e essas coisas tive-as e continuo a tê-las. É-me muito fácil estar no meio de quarenta pessoas e arranjar "um quarto" para mim onde consiga escrever.

MTC: Escrever poesia é prazer ou sofrimento? Acontece de forma ensaiada ou é tomada de assalto a meio da noite?

ALA: Acho que a poesia é as duas coisas, prazer e sofrimento. Em vez de lhe chamar sofrimento, chamar-lhe-ia antes angústia. Angústia da palavra que não sai, dos desenhos que acompanham a criação dos poemas e representam a palavra que se quer dizer, mas não se consegue. Embora tenha essa angústia, ela é atravessada por um imenso prazer. Não é por masoquismo que escrevo poesia, nem porque me traga compensações. Eu escrevo poesia porque preciso de escrever poesia.

MTC: E é pensada? Faz esboços dos poemas? Ou é assaltada pela inspiração?

ALA: Depende. As duas coisas são possíveis. Geralmente não é pensada. O primeiro poema do meu livro Imagens não foi pensado, mas posteriormente achei que seria interessante contar uma história. Sendo o meu livro mais autobiográfico, acabou por se tornar também o meu livro mais cifrado. A parte da ideia, da escrita, não é pensada, porque eu não a controlo. É o poema que me controla a mim. A fase seguinte, de trabalhar e de o passar para o computador ou para a máquina de escrever, é mais mecânica. Há um poema lindíssimo de Emily Dickinson que traduzi e que diz "Shall I take thee, the Poet said / to the propounded word?", em que a poeta vê uma série de palavras à sua frente que se declaram, e escolhe a que pretende. Finalmente, quando escolhe aquela palavra, há outra que surge sem ser chamada. E essa é a inspiração, que entra de forma desviada, "pelas traseiras", como um ladrão.

MTC: Luíza Neto Jorge dizia que "o poeta é um animal longo desde a infância”. O que é para si o poeta?

ALA: Se calhar começava com o poema, em vez do poeta. Eu tenho um poema, que nunca publiquei, e que diz "Todo o poema é sobre aquele que sobre ele escreve." E eu sempre pensei assim, mesmo na altura em que se achava que a poesia era só oficina. A poesia não é só oficina. Eu ensino literatura e há 30 anos que ensino poesia, e é precisamente o lado que escapa à oficina que permanece um mistério que eu não consigo desvendar. Preferia não falar em dom, mas em talento. Um talento que nasce com quem escreve e que pode ou não ser exercitado.

MTC: Não se aprende, portanto, a escrever?

ALA: Não. Não acho que se aprenda a escrever. Aprende-se a desenvolver a sensibilidade, aprende-se a tradição, que é fundamental. Aprender a ler outros poetas e essa leitura pode ser absolutamente fascinante, devastadora, "exhilarating" como se diz em inglês. Pode ser algo que nos inspira, mas não se aprende a fazer um poema. Lembro-me de ter três anos e meio e ouvir uma quadra e saber que faltava ali qualquer coisa. E essa "qualquer coisa" 
era uma sílaba a mais ou a menos. Nunca precisei de contar pelos dedos para saber o que é um decassílabo, sem que eu soubesse ainda a designação dessa palavra. Mas sabia que dizer "amor é fogo que arde sem se ver, é ferida que dói e não se sente" era quase a perfeição. Lembro-me que o primeiro contacto que tive com Camões foi numa papelaria que havia ao pé da minha escola, em que Camões aparece com um olho tapado e, por baixo, estava precisamente esse verso, e eu perguntava-me como é que alguma coisa pode arder sem ser vista. Trata-se do espanto, do maravilhamento. E isso não se ensina.

MTC: Mais uma vez, parti de parte do poema "Testamento", do seu livro Minha Senhora de Quê, onde diz :

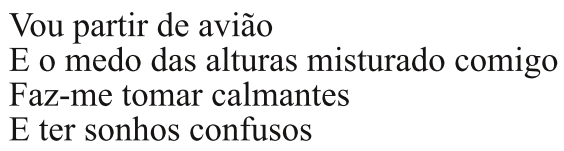

MTC: Tem medo de morrer?

ALA: Muito medo de morrer. Tenho pavor de morrer.

MTC: Como é que encara a morte?

ALA: Pessimamente. Acho que é uma coisa injustíssima, horrível, que não devia acontecer nunca. Acho que é um disparate aquele argumento de quão terrível seria se fossemos imortais e continuássemos a envelhecer. Eu não me importava, desde que estivesse viva - e a pensar. Não sei se há ou não outro nível de consciência, gostava que houvesse, seria maravilhoso. Mas eu queria era este nível de consciência. Se reencarnar, não me lembro deste sítio onde estive, e o que é certo é que, mesmo sofrendo, é maravilhoso estar aqui.

MTC: Shakespeare dizia que escrevia para ser imortal. A Ana Luísa escreve com o mesmo propósito?

ALA: Não. E o que Shakespeare diz é "So long as men can breathe,/ or eyes can see, / so long lives this / and this gives life to thee", ou seja, a ideia é "tu viverás através dos meus poemas, mesmo quando eu morrer, mesmo quando tu morreres". Há um lado meu que pensa assim, já que esta "brincadeira" vai acabar. Dickinson diz, num poema dirigido a Deus, "In thy long paradise of light, no moment will there be, when $i$ shall long for earthly play and mortal company". Claro que a homofonia e homografia entre "long" e "long", "longo" e "saudades", empresta uma ironia ao poema, que significa que, na verdade, a poeta vai ter saudades disto, deste lugar, porque o resto, "o longo paraíso de luz", não tem imperfeições, e, portanto, não tem desejos. Já que eu vou ter de abandonar este lugar, todos nós temos, obviamente que gostava muito que os meus poemas ficassem. Mas só o tempo pode dar o valor às coisas. É sempre muito perigoso falarmos do que está hoje a acontecer sobre nós, mesmo em cima de nós, porque a nossa percepção é sempre muito viciada.

MTC: A Ana Luísa não sabe se os seus poemas vão ficar?

ALA: Não sei, não faço ideia. É um sonho que tenho. 
MTC: Quais são os poemas que ficam?

ALA: Essa pergunta leva-nos para uma conversa complicada sobre a própria questão da Arte e dos mecanismos de legitimação da Arte. Como é que se fazem os mecanismos da legitimação da arte? Obviamente que tem que se passar sempre pela crítica, mas é necessário que passe também pelas pessoas. As pessoas que não são especialistas e que amam o poema pelo poema, a quem o poema diz porque diz e que nem sequer têm uma metalinguagem para teorizar sobre o poema, porque não precisam de ter. Por alguma razão, a primeira edição da poesia de Dickinson teve um sucesso estrondoso, mesmo tratando-se de uma poeta tão difícil de ler. Mas alguém que diz que “amor é tudo o que há, / é tudo o que sabemos do amor" e que o define assim, obviamente que toca as pessoas. Quem é que não conhece "Senhora, partem tam tristes meus olhos por vós, meu bem"? As pessoas não sabem que o autor é João Roiz Castel-Branco, não sabem que pertence ao Cancioneiro Geral, mas também não interessa, porque o poema diz-nos tanto, comunica tanto, que é isso que vale a pena. E aí chegamos ao ponto fundamental. A arte é comunicação. Ninguém escreve para a gaveta. O público pode ser um, um amigo, um irmão, um tio, mas sendo um, já é um público. Um pintor tem necessidade de mostrar aquilo que faz, um músico tem necessidade de ser ouvido. E essa troca faz-se com as pessoas "normais", da rua, que muitas vezes podem não perceber o poema, no seu sentido académico, mas que são tocadas por um verso. Noutro dia, fui fazer uma leitura de poemas e uma senhora veio ter comigo e disse-me "Não imagina, isto fez por mim o que dois anos de anti-depressivos não fizeram." E eu acho que isso é que interessa. Não é agora o crítico xis ou ípsilon vir elaborar uma grande teoria sobre o poema. Eu também faço isso com os poemas dos outros, quando ensino e escrevo sobre poesia, mas o que é inegável é que o que nos fíca, dos Lusíadas, por exemplo, é o episódio de Inês de Castro. Porque é um episódio universal, sobre o amor, a tristeza, o sofrimento e a injustiça. É simultaneamente um episódio poético e político e portanto, humano. O que vai ficar é o humano.

MTC: Trocava mesmo, como uma vez disse, "toda a poesia que escrevi por viver outra vez"?

ALA: Não. É mentira. (risos) Eu compus o livro a que pertence esse poema, quando tinha sido operada e fui obrigada a ficar um mês de cama. Mandei os poemas por e-mail a Maria Irene Ramalho, que foi a pessoa que me incentivou, aos 32 anos, a publicar o meu primeiro livro. Esse poema começa precisamente assim, "Trocava a poesia toda que escrevi por viver outra vez, / é essa (ao que parece) a minha (freudiana) fantasia" e a Maria Irene fez vários comentários a todos os poemas e, sobre esse, disse "Não trocavas nada, mentirosa!". E é verdade. É um desabafo poético que fica bem num momento de lirismo, mas, depois de saber o que

sei hoje, não trocava, não.

MTC: Ana Luísa, Senhora de Quê?

ALA: Senhora de nada. Nem de mim. E por isso mesmo, espero, mais livre. 